\title{
COMPARISON OF THE INFLUENCE OF "SOLVENT/NON-SOLVENT" TREATMENT FOR THE ATTACHMENT OF SIGNAL MOLECULES ON THE STRUCTURE OF ELECTROSPUN PCL AND PLLA BIODEGRADABLE SCAFFOLDS
}

\author{
Semen Goreninskii ${ }^{a}$, Ksenia Stankevich, Evgeny Bolbasov, Nadezhda Danilenko, \\ Victor Filimonov, Sergei Tverdokhlebov \\ ${ }^{1}$ National Research Tomsk Polytechnic University, 634050, Tomsk, Russia
}

\begin{abstract}
Electrospun biodegradable scaffolds (matrixes) made of poly( $\varepsilon$ caprolactone) (PCL) and poly(L-lactic acid) (PLLA) are three-dimensional fibrous structures that are commonly used in regenerative medicine and drug delivery systems. Modification of such structures allows manipulating with biological and immune response. Previously, our team suggested a number of surface modification strategies for thin films made of PLLA. One of the proposed strategies are based on treatment of the material with "solvent/non-solvent" mixture that allows absorbing biologically active molecules or linkers on the surface of the sample. The aim of this work was to compare the influence of "solvent/non-solvent" treatment on the structure and crystallinity of the elecrospun biodegradable PCL and PLLA scaffolds. For that purpose, original PCL and PLLA scaffolds were treated with mixture of toluene and ethanol in different proportions. Morphology of the obtained samples was studied using scanning electron microscopy. It was shown that "solvent/non-solvent" treatment doesn't lead to changes in scaffolds morphology such as gluing or cutting of the matrix fibers. By means of X-ray diffraction analysis it was shown that treatment of the samples with selected mixtures doesn't change material crystallinity. Thus, it was demonstrated that proposed composition of the "solvent/nonsolvent" mixture can be used for the modification of electrospun PCL and PLLA scaffolds.
\end{abstract}

\section{Introduction}

Poly(L-lactic) acid (PLLA) and poly( $\varepsilon$-caprolactone) are biodegradable polymers widely applied in modern medicine [1]. Because of their outstanding properties, such as degradability [2], processability [3] and biocompatibility [4] these materials are used in production of the wide range of biomedical devices such as catheters [5], coronary stents [6], and implants [7].

\footnotetext{
${ }^{a}$ Corresponding author: semgor93@gmail.com
} 
However, a number of complications arise due to the relative chemical inertness of these materials including a lack of biological activity, irritation and inflammation processes. In order to improve the surface properties of PLLA thin films both physical [8] and chemical [9] methods may be applied.

Solution blow spinning (SBS) [10] and electrospinning (ES) [11] are common techniques allow for the production of free-dimensional fibrous structures called matrixes (scaffolds). Because of their specific architecture, biodegradable scaffolds are being used in tissue engineering as an extracellular matrix for support of the cell growth [12]. Moreover, their biodegradability and controllable degradation rate give an opportunity for the target drug delivery [13].

Previously our team reported a number of PLLA modification strategies. One of them allows attachment of biologically active molecules and reactive groups on the surface of the material and based on treatment of the polymer with "solvent/non-solvent" mixture (Figure 1) $[14,15]$. It was suggested that proposed modification method may be applied on the other biodegradable polymers such as PCL.

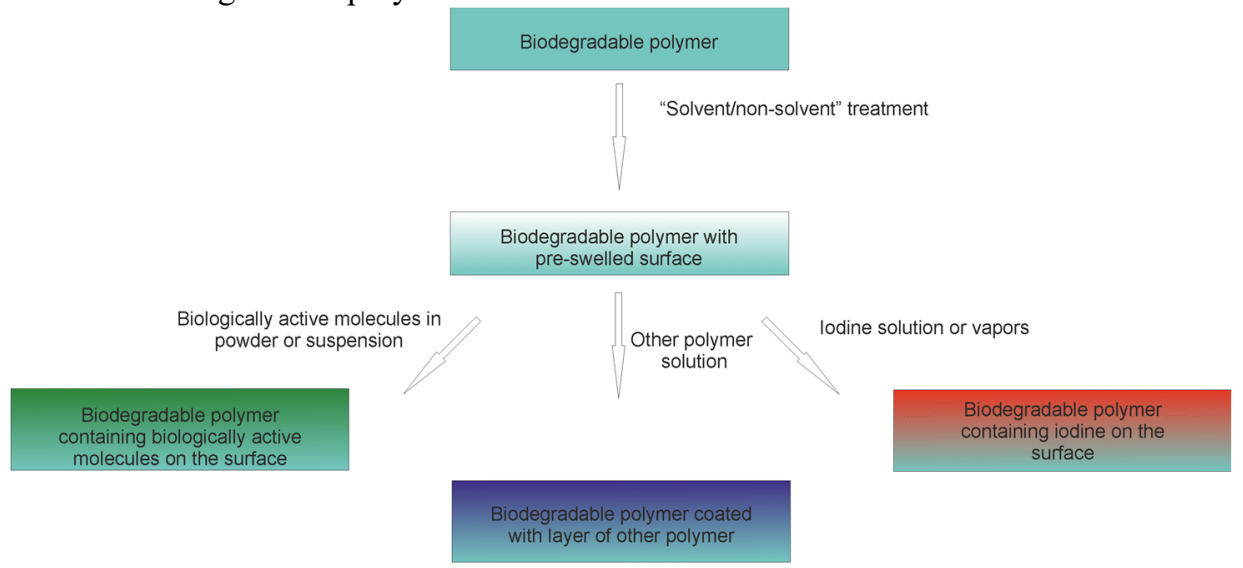

Figure 1. Proposed method for the modification of biodegradable polymers.

The aim of our research was to identify the possibility of application of such method for the modification of electrospun PCL and PLLA scaffolds and to reveal convenient modification conditions. The influence of the treatment on the structure of both materials was compared. In order to investigate the influence of "solvent/non-solvent" treatment on the morphology of the samples scanning electron microscopy (SEM) was used. In addition, $\mathrm{X}$-ray diffraction analysis was applied for investigation of the changes of the material crystallinity after the treatment.

\section{Materials and methods}

\subsection{Preparation of nonwoven materials}

All polymer solutions were prepared in a sealed glass reactor at a room temperature. Electrospinning process was performed on NANON-01A (Mecc Co., Japan) equipment. The electrospun nanofibers were placed on a frame cylinder collector (a diameter of 100 $\mathrm{mm}$, a length of $210 \mathrm{~mm}$ ) with a rotation speed of $50 \mathrm{rpm}$. The distance between syringe tip and collector was $150 \mathrm{~mm}$ for PLLA (PL 38, Purasorb, $M_{\mathrm{w}}=670000 \mathrm{~g} / \mathrm{mol}$ ) and $190 \mathrm{~mm}$ for PCL (PCL, Sigma-Aldrich, $\mathrm{M}_{\mathrm{w}}=70000-90000 \mathrm{~g} / \mathrm{mol}$ ). PLLA matrixes were prepared from $3 \%(\mathrm{w} / \mathrm{w})$ solution in chloroform under the following conditions: voltage of $27 \mathrm{kV}$, feed 
rate of $6 \mathrm{~mL} / \mathrm{h}$. For PCL matrixes production the following parameters were used: voltage of $20 \mathrm{kV}$, feed rate of $6 \mathrm{~mL} / \mathrm{h}$.

\section{2 "Solvent/non-solvent" treatment of the electrospun scaffolds}

In order to investigate the influence of the "solvent/non-solvent" treatment on the properties of PLLA and PCL electrospun scaffolds, the original materials were soaked in the mixture of toluene and ethanol in different proportions (1/9, 0.9/9.1, 0.8/9.2, 0.7/9.3, 0.6/9.4, $0.5 / 9.5, \mathrm{v} / \mathrm{v}$ ) for 10 minutes. Then, all the samples were placed in vacuum for 24 hours to remove residual solvents.

\subsection{Scanning electron microscopy}

For analysis of the scaffolds morphology scanning electron microscopy (SEM, ESEM Quanta 400 FEG, FEI, USA) was used. All the samples were pre-coated with gold using Smart Coater (Jeol, Japan) sputtering system. The scanning was carried out at a high vacuum, with accelerating voltage of $20 \mathrm{kV}$ and magnification of 1000 and 21000 times. Diameter of material fibers was measured by using ImageJ 1.38 software (National Institutes of Health, USA).

\subsection{X-ray diffraction analysis}

The crystalline structure of the samples was investigated by means of X-ray diffraction analysis (DRON-3M, Russia). During the analysis all samples were irradiated with $\mathrm{Cu}$ Kradiation with a wavelength of $1.54056 \AA$ under following parameters: accelerating voltage of $35 \mathrm{kV}$, beam current of $25 \mathrm{~mA}$ and scanning rate of $4 \% \mathrm{~min}$. Scanning angle range was from $12^{\circ}$ to $22^{\circ}$ and from $21^{\circ}$ to $26^{\circ}$ for PLLA and PCL matrixes respectively. The average crystal size of the samples was calculated according to Debye-Scherrer equation:

$$
l_{c}=\frac{\kappa \lambda}{\cos \theta \sqrt{\beta^{2}-\beta_{r}^{2}}},
$$

where $\kappa=0.9, \lambda$ is the wavelength if the incident radiation, $\beta$ is the width of the reflection at a half height, $\beta_{r}$ is the broadening reflex of the apparatus, $\theta$ is the angle of diffraction.

\subsection{Statistics}

Statistical analysis was performed in Prism (GraphPad Software, USA) software. Nonparametric Mann-Whitney test was used.

\section{Results and discussion}

\subsection{Scaffolds morphology}

SEM images of the original and treated PCL and PLLA scaffolds are shown in the Figure 2. 

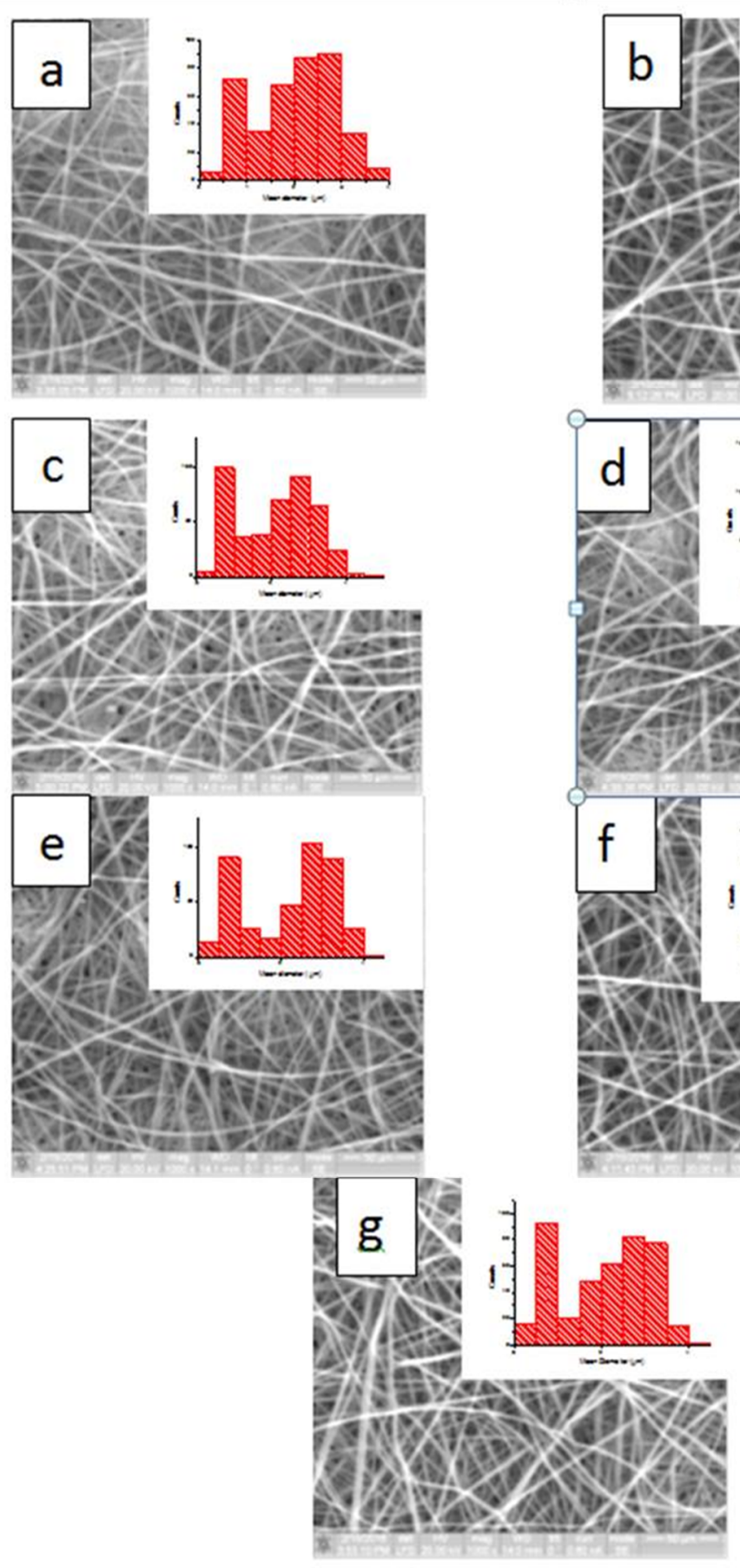

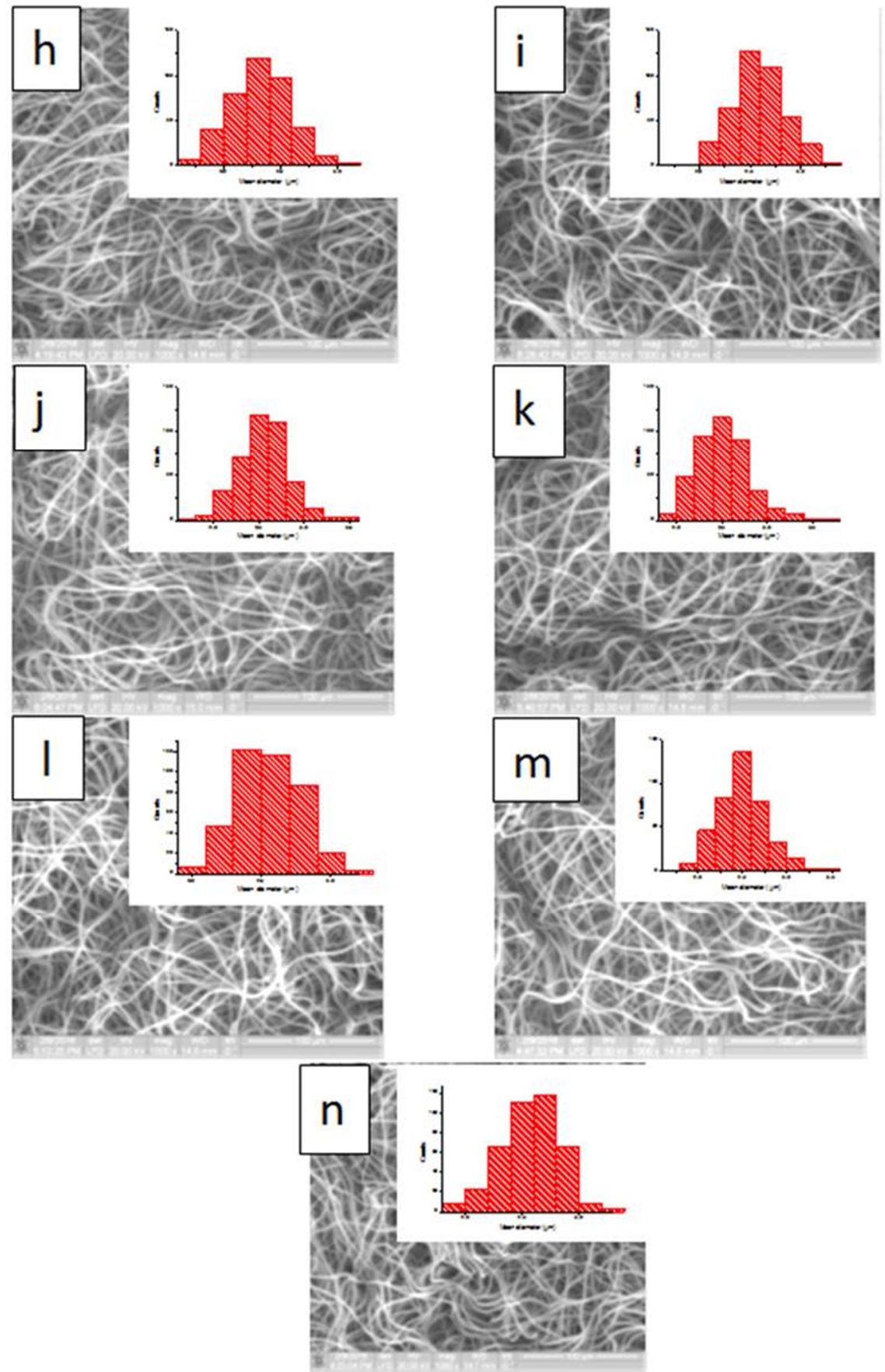

Figure 2. SEM images of the obtained samples, where:

a - non-treated PCL scaffold, PCL scaffolds, treated with mixture of toluene and ethanol in different proportions: $\mathrm{b}-0.5 / 9.5, \mathrm{v} / \mathrm{v}, \mathrm{c}-0.6 / 9.4, \mathrm{v} / \mathrm{v}, \mathrm{d}-0.7 / 9.3, \mathrm{v} / \mathrm{v}, \mathrm{e}-0.8 / 9.2, \mathrm{v} / \mathrm{v}, \mathrm{f}-0.9 / 9.1, \mathrm{v} / \mathrm{v}, \mathrm{g}-1 / 9$, $\mathrm{v} / \mathrm{v} ; \mathrm{h}$ - non-treated PLLA scaffold, PLLA scaffolds, treated with mixture of toluene and ethanol in different proportions: $\mathrm{i}-0.5 / 9.5, \mathrm{v} / \mathrm{v}, \mathrm{j}-0.6 / 9.4, \mathrm{v} / \mathrm{v}, \mathrm{k}-0.7 / 9.3, \mathrm{v} / \mathrm{v}, 1-0.8 / 9.2, \mathrm{v} / \mathrm{v}, \mathrm{m}-0.9 / 9.1$, $\mathrm{v} / \mathrm{v}, \mathrm{n}-1 / 9, \mathrm{v} / \mathrm{v}$. 
It was found that produced PCL scaffolds have bimodal distribution of the fiber diameter, whereas PLLA scaffolds demonstrate unimodal distribution. Mean diameter of the fibers was calculated from not less than 400 measurements on each image. Changes of the mean diameter of the fibers are presented in Figure 3.

a)

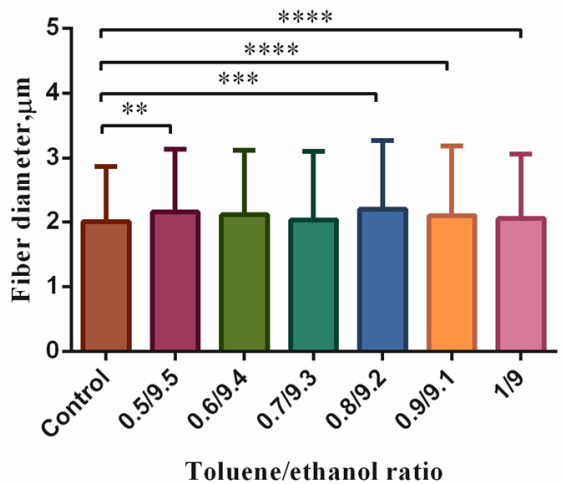

b)

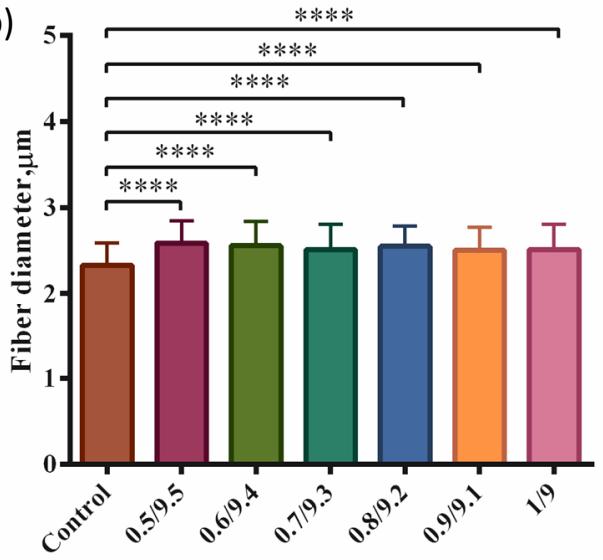

Toluene/ethanol ratio

Figure 3. Mean diameter of the scaffolds after the treatment with mixture of toluene and ethanol in different proportions: a) PCL b) PLLA $\left(* * * * \mathrm{p}<0.0001, * * * \mathrm{p}<0.001,{ }^{* *} \mathrm{p}<0.01\right)$.

It was found that in most cases "solvent/non-solvent" treatment leads to a statistically significant increase of the fibers diameter. On the other hand, fibrous structure of the material wasn't changed: gluing or cutting of the fibers was not observed.

Thus, toluene/ethanol mixture in proportion of $1 / 9(\mathrm{v} / \mathrm{v})$ was selected for further modifications of PCL as well as PLLA scaffolds as it contains more solvent for better preswelling of the polymer surface.

\subsection{X-ray diffraction analysis}

Figure 4 show representative XRD patterns of the obtained samples of PCL and PLLA scaffolds.
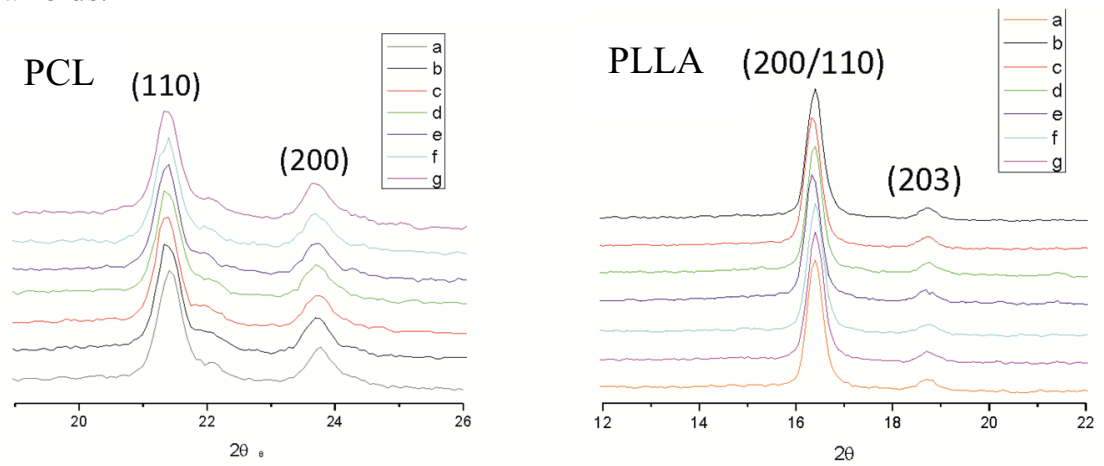

Figure 4. XRD patterns of PCL and PLLA scaffolds, where:

PCL: $a$ - non-treated PCL scaffold, PCL scaffolds, treated with mixture of toluene and ethanol in different proportions: $b-0.5 / 9.5, \mathrm{v} / \mathrm{v}, c-0.6 / 9.4, \mathrm{v} / \mathrm{v}, d-0.7 / 9.3, \mathrm{v} / \mathrm{v}, e-0.8 / 9.2, \mathrm{v} / \mathrm{v}, f-0.9 / 9.1, \mathrm{v} / \mathrm{v}$, $g-1 / 9, \mathrm{v} / \mathrm{v}$; PLLA: $a$ - non-treated PLLA scaffold, PLLA scaffolds, treated with mixture of toluene and ethanol in different proportions: $b-0.5 / 9.5, \mathrm{v} / \mathrm{v}, c-0.6 / 9.4, \mathrm{v} / \mathrm{v}, d-0.7 / 9.3, \mathrm{v} / \mathrm{v}, e-0.8 / 9.2, \mathrm{v} / \mathrm{v}$, $f-0.9 / 9.1, \mathrm{v} / \mathrm{v}, g-1 / 9, \mathrm{v} / \mathrm{v}$. 
XRD patterns of the produced PCL scaffolds are presented by two reflections in $21.3^{\circ}$ and $23.7^{\circ}$ regions, corresponding to (110) and (200) plates. No additional reflexes were found after the treatment. Average size of PCL and PLLA crystallites, calculated according to the equation (1), is shown in the Table 1. In XRD patterns of PLLA scaffolds reflexes appearing in two areas: $16.4^{\circ}$ and $18.8^{\circ}$, corresponding to (200/110) and (203) plates. No additional reflexes were found after the treatment. For PCL and PLLA scaffolds "solvent/non-solvent" treatment had no influence on the phase structure of the polymer. Thus, according to the obtained data, "solvent/non-solvent" treatment didn't lead to the formation of additional phases.

Table 1. Average size of PCL and PLLA crystallites.

\begin{tabular}{|c|c|c|}
\hline $\begin{array}{c}\text { Proportions of toluene } \\
\text { and ethanol, } \mathrm{v} / \mathrm{v}\end{array}$ & $\begin{array}{c}\text { Average crystallite size of PCL } \\
\text { scaffolds, treated with mixture of } \\
\text { toluene and ethanol, nm }\end{array}$ & $\begin{array}{l}\text { Average crystallite size of PLLA } \\
\text { scaffolds, treated with mixture of } \\
\text { toluene and ethanol, nm }\end{array}$ \\
\hline Non-treated & $19.35 \pm 0.61$ & $21.61 \pm 0.38$ \\
\hline $0.5 / 9.5$ & $19.80 \pm 0.65$ & $21.05 \pm 0.32$ \\
\hline $0.6 / 9.4$ & $19.35 \pm 0.59$ & $21.05 \pm 0.31$ \\
\hline $0.7 / 9.3$ & $19.51 \pm 0.70$ & $21.24 \pm 0.55$ \\
\hline $0.8 / 9.2$ & $19.48 \pm 0.21$ & $21.61 \pm 0.33$ \\
\hline $0.9 / 9.1$ & $19.35 \pm 0.61$ & $20.69 \pm 0.53$ \\
\hline $1 / 9$ & $18.89 \pm 0.28$ & $21.07 \pm 0.83$ \\
\hline
\end{tabular}

Statistical analysis indicated that treatment with "solvent/non-solvent" mixture with all the selected compositions has no significant effect on the size of PCL crystals. Size of PLLA crystals also didn't change significantly after "solvent/non-solvent" treatment.

As no influence on the crystal structure of the polymer was observed with toluene concentration increase, the mixture of toluene and ethanol $(1 / 9, \mathrm{v} / \mathrm{v})$ was chosen for further experiments.

\section{Conclusion}

The influence of "solvent/non-solvent" treatment on the structure of electrospun nanofibrous scaffolds made of poly( $\varepsilon$-caprolactone) and poly(L-lactic) acid was compared. It was shown, that treatment with "solvent/non-solvent" mixtures containing toluene and ethanol in different proportions has no crucial effect on the structure and crystallinity of both materials. Thus, this solvent system will be used for the attachment of signal molecules on the biodegradable scaffolds surface for programming and regulating of biological and immune response.

\section{Acknowledgements}

This research was funded by Russian Science Foundation (project № 16-13-10239) and performed in Tomsk Polytechnic University.

\section{References}

[1] H. Tian, Z. Tang, X. Zhuang, X. Chen, X. Jing, Prog. Polym. Sci. 37, 237 (2012) doi: 10.1016/j.progpolymsci.2011.06.004 
[2] T. Ishigaki, W. Sugano, A. Nakanishi, M. Tateda, M. Ike, M. Fujita, Chemosphere 54, 255 (2004) doi: 10.1016/S0045-6535(03)00750-1

[3] S. Frackowiak, J. Ludwiczak, K. Leluk, M. Kozlowski, Compos Part B-Eng. 92, 1 (2016) doi: 10.1016/j.compositesb.2016.02.036

[4] L. Wu, L. Wang, X. Wang, K. Xu, Acta Biomater 6, 1079 (2010)

[5] I. Gradus-Pizlo, R.L. Wilensky, K.L. March, N. Fineberg, M. Michaels, G.E. Sandusky, D.R. Hathaway, J. Am. Col. Cardiol. 26, 1549 (1995) doi: 10.1016/0735-1097(95)00345-2

[6] C.M. Bünger, N. Grabow, K. Sternberg, C. Kröger, L. Ketner, K.-P. Schmitz, H.J. Kreutzer, H. Ince, C.A. Nienaber, E. Klar, W. Schareck, J. Surg. Res. 139, 77 (2007) doi: $10.1016 /$ j.jss.2006.07.035

[7] K.E. Uhrich, D. Abdelhamid, Biosynthetic Polymers for Medical Applications, 63 (2016) doi: 10.1016/B978-1-78242-105-4.00003-1

[8] R. Morent, N. De Geyter, T. Desmet, P. Dubruel, C. Leys, Plasma Process. Polym. 8,171 (2011) doi: 10.1002/ppap.201000153

[9] R.M. Rasal, A.V. Janorkar, D.E. Hirt, Prog. Polym. Sci. 35, 338 (2010) doi: 10.1016/j.progpolymsci.2009.12.003

[10] E.N. Bolbasov, Y.G. Anissimov, A.V. Pustovoytov, I.A. Khlusov, A.A. Zaitsev, K.V. Zaitsev, I.N. Lapin, S.I. Tverdokhlebov, Mater. Sci. Eng. C 40, 32 (2014) doi: 10.1016/j.msec.2014.03.038

[11] A. Moheman, M.S. Alam, A. Mohammad, Adv. Colloid. Interfac. 229, 1 (2016) doi: $10.1016 /$ j.cis.2015.12.003

[12] S. Beke, R. Barenghi, B. Farkas, I. Romano, L. Körösi, S. Scaglione, F. Brandi, Mater. Sci. Eng. C 44, 38 (2014) doi: 10.1016/j.msec.2014.07.008

[13] G.N. Abdelrasoul, B. Farkas, I. Romano, A. Diaspro, S. Beke, Mater. Sci. Eng. C 56, 305 (2015) doi: 10.1016/j.msec.2015.06.037

[14] K.S. Stankevich, A. Gudima, V.D. Filimonov, H. Klüter, E.M. Mamontova, S.I. Tverdokhlebov, J. Kzhyshkowska, Mater. Sci. Eng. C 51, 117 (2015) doi: 10.1016/j.msec.2015.02.047

[15] V. D. Filimonov, K. S. Stankevich, S. I. Goreninsky, N. V. Danilenko, S. I. Tverdokhlebov, 3rd International Conference on Chemical Technology: Book of Abstracts, 49 (2015) 